\title{
ROLE OF CALCIUM FOR MAGNESIUM-ACTIVATED ADENOSINETRIPHOSPHATASE ACTIVITY AND ADENOSINETRIPHOSPHATE-MAGNESIUM STIMULATED CATECHOLAMINE RELEASE FROM ADRENAL MEDULLARY GRANULES
}

\author{
Futoshi IZUMI, Motoo OKA and Takeshi KASHIMOTO \\ Department of Pharmacology, Faculty of Medicine, Osaka University, Kita-ku, Osaka
}

Received for publication June 23, 1971

There have been several reports that $\mathrm{Mg}^{++}$-activated ATPase is present in the catecholamine storage granules of the adrenal medulla (1-3) and that this ATPase may be linked in some way with the ATP- $\mathrm{Mg}^{++}$stimulated uptake and release of catecholamine by isolated granules (4-9).

Recently, we found that the low concentration of $\mathrm{Ca}^{++}$present in the incubation medium as a contaminant participated in the release of catecholamine from the granules stimulated by ATP and $\mathrm{Mg}^{++}(10)$. This finding is interesting in relation to the fact that acetylcholine or excess potassium causes the release of catecholamine from a perfused adrenal gland by promoting increased uptake of $\mathrm{Ca}^{++}$into the cells (11-13).

This paper reports investigations on the effect of $\mathrm{Ca}^{++}$on the $\mathrm{Mg}^{++}$-activated ATPase activity in isolated catecholamine storage granules from the adrenal medulla. The possible relationship of these results to the release of catecholamine from the granules is discussed.

\section{MATERIAL AND METHODS}

\section{1) Preparation of catecholamine storage gramules from adrenal medulla}

Catecholamine storage granules were prepared from bovine adrenal medulla as described previously (14). After removal of the cortex, the medullary tissue was cut into pieces and homogenized in a glass Potter homogenizer with $5-6$ volumes of $0.32 \mathrm{M}$ sucrose containing $40 \mathrm{~mm}$ of Tris- $\mathrm{HCl}$ buffer $(\mathrm{pH} 7.3)$. The homogenate was centrifuged at $1,000 \times g$ for 10 min to remove coarse debris and nuclei. The supernatant was passed through membrane filters as described previously (14). The filtrate passing through a $0.3 \mu$ pore filter was then centrifuged at $6,000 \times \mathrm{g}$ for 20 minutes. The pellet was suspended with isotonic $\mathrm{KCl}$ solution $(150 \mathrm{~mm} \mathrm{KCl}, 40 \mathrm{~mm}$ Tris-HCl buffer, $\mathrm{pH} \mathrm{7.3)}$ and centrifuged again at $6,000 \times g$ for 20 minutes. The pellet was finally suspended in isotonic $\mathrm{KCl}$ solution and used as the preparation of catccholamine slorage granules.

2) Measurement of ATPase acivity of granules

The standard incubation medium contained $150 \mathrm{~mm} \mathrm{KCl}, 40 \mathrm{~mm}$ Tris- $\mathrm{HCl}$ buffer ( $\mathrm{pH}$ 7.3), $4 \mathrm{~mm} \mathrm{ATP} \mathrm{and} 2 \mathrm{~mm} \mathrm{MgSO}_{4}$. The reaction was started by adding the granules (about $2 \mathrm{mg}$ of protein, containing 400-500 $\mu \mathrm{g}$ of catecholamine). The final volume of the incu- 
bation mixture was $4 \mathrm{ml}$. The reaction was stopped by adding $1 \mathrm{ml}$ of $50 \%(\mathrm{w} / \mathrm{v})$ trichloroacetic acid. After deproteinization the inorganic phosphate in the supernatant was estimated following the method of Takahashi et al. (15). Protein was estimated according to Lowry et al. (16).

3) Release of catecholamine from the granules

The reaction was carried out in plastic centrifuge tubes without shaking. The standard incubation medium was the same as that used for measurement of the ATPase activity of the granules. The reaction was terminated by adding $4 \mathrm{ml}$ of ice cold isotonic $\mathrm{KCl}$ solution. Then the tubes were immediately chilled in ice and centrifuged at $20,000 \times \mathrm{g}$ for 10 minutes. Catecholanine in the precipitale and supernatant were extracted with $0.4 \mathrm{~N}$ perchloric acid and determined fluorimetrically by the ethylenediamine condensation method (17).

4) Reagents

ATP, disodium salt was obtained from Sigma Chemical Co., passed through a Dowex $50\left(\mathrm{H}^{+}\right.$type, $\left.200-400 \mathrm{mesh}\right)$ column $(0.4 \mathrm{~cm} \times 4 \mathrm{~cm})$ to remove contaminating calcium ions and converted to the tris-form.

Ca-EGTA was prepared by mixing various ratios of $\mathrm{CaCl}_{2}$ and *EGTA following the method of Portzehl et al. (18). The mixture was adjusted to $\mathrm{pH} 7.3$ by addition of $\mathrm{KOH}$.

\section{RESULTS}

1) Effects of EGTA on $\mathrm{Mg}^{++}$-activated ATPase and ATP-Mg${ }^{++}$stimulated catecholamine release

The $\mathrm{Mg}^{++}$-activated ATPase activity of the gramules and the ATP-Mg+t stimulated catecholamine release in the presence of various concentrations of $\mathrm{Mg}^{++}$were examined. Incubation was carried out at $37 \mathrm{C}$ for 5 minutes. The release of catecholamine from the granules was strongly stimulated by tho addition of ATP- $\mathrm{Mg}^{++}$in parallel with activation of $\mathrm{Mg}^{++}$-activated ATPase. As shown in Fig. 1, $\mathrm{Mg}^{++}$-activated ATPase aclivity was inhibited significantly by addition of $2.5 \mathrm{~mm}$ of EGTA, which chelates with calcium. This inhibitory effect of EGTA was not affected by the increase of $\mathrm{Mg}^{++}$concentration in the incubation medium.

The ATP- $\mathrm{Mg}^{++}$stimulated release of catecholamine was examined under

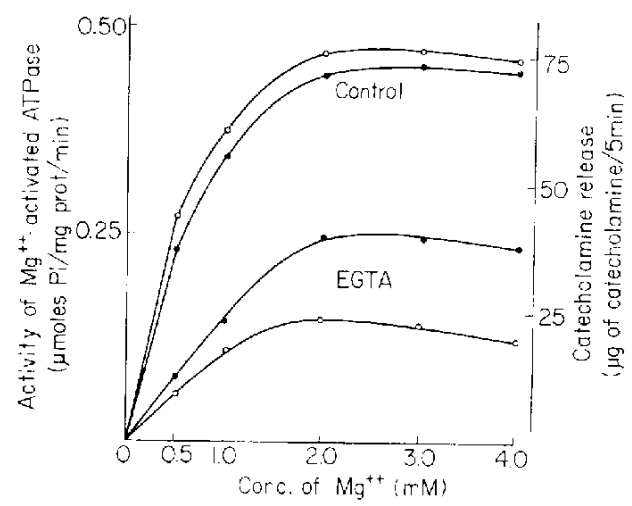

FIG. 1. Inhibitory effect of EGTA on $\mathrm{Mg}^{++}$. activated ATPase of adrenal medullary granules and ATP- $\mathrm{Mg}^{++}$stimulated catecholamine release.

The reaction was carried out in standard incubation medium for 5 minutes at $37^{\circ} \mathrm{C}$. EGTA (2.5 mM) was present or absent. The values are the means of 5 experiments.

-1- $\mathrm{Mg}^{++}$-activated ATPase activity $\bigcirc-O$ ATP-Mg ${ }^{++}$stimulated catechomaline release

*EGTA; 1,2-bis (2-dicarboxymethylaminoethoxy)-ethane 
the same experimental conditions. ATP$\mathrm{Mg}^{++}$stimulated release of catecholamine was reduced to $35 \%$ of the control value by addition of $2.5 \mathrm{~mm}$ EGTA. The inhibitory effect of EGTA on catecholamine release was much stronger than the effect of $\mathrm{Mg}^{++}$-activated ATPase.

EGTA did not interfere with the assay of inorganic phosphate or catecholamine, since it had no affect when added to the sample after the reaction had stopped.

2) Reversal by Ca-EGTA of EGTA inhibition of $\mathrm{Mg}^{++}$-activated ATPase and $\mathrm{ATP}-\mathrm{Mg}^{++}$stimulated catecholamine release

To confirm that the effect of EGTA was due to its chelation with contaminating $\mathrm{Ca}^{++}$, the ratio of $\mathrm{Ca}^{++}$to EGTA was varied keeping the EGTA concentration at $2.5 \mathrm{~mm}$. In intact granules,

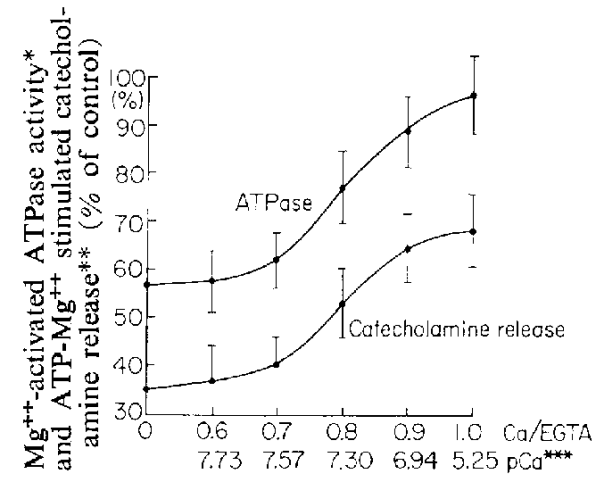

FIG. 2. $\mathrm{Mg}^{++}$-activated ATPase activity of adrenal medullary granules and ATP$\mathrm{Mg}^{++}$stimulated catecholamine release at various Ca-EGTA ratios.

Reactions were carried out for $5 \mathrm{~min}-$ utes at $37^{\circ} \mathrm{C}$ in standard incubation medium but with various $\mathrm{Ca} / \mathrm{EGTA}$ ratios. The values represent the means of 5 experiments and standard deviation are indicated by vertical I-shaped bars.

* $100 \%$ activity $=0.43 \pm 0.04 \mu$ moles $\mathrm{Pi}$ ? $\mathrm{mg}$ prot/minutes

** $100 \%$ catecholamine release $=75 \pm 9.0$ $\mu \mathrm{g} / 5$ minutes

*** $\mathrm{pCa}$; Calculated value of free $\mathrm{Ca}^{++}$

the inhibition of $\mathrm{Mg}^{++}$-activated ATPase by EGTA was progressively reversed on raising the $\mathrm{Ca} / \mathrm{EGTA}$ ratio (Fig. 2). Addition of $\mathrm{CaCl}_{2}$ at a concentration equivalent to that of EGTA almost completely prevented the inhibition by EGTA.

The inhibition of ATP- $\mathrm{Mg}^{++}$stimulated release of catecholamine by EGTA was also reversed by raising the $\mathrm{Ca} / \mathrm{EGTA}$ ratio. However, even in the presence of equimolar amounts of $\mathrm{Ca}^{++}$and EGTA catecholamine release increased to about $70 \%$ of the control value.

3) Effects of EGTA and Ca-EGTA on $\mathrm{Mg}^{++}$-activated ATPase in catecholamine storage granules in hypotonic $\mathrm{KCl}$ solution

Next, the effects of EGTA and Ca-EGTA were examined in hypotonic $\mathrm{KCl}$ (25 mM) solution in which the granules ruptured abruptly, to see whether the inhibitory effect of EGTA on $\mathrm{Mg}^{++}$-activated ATPase was dependent on intact structure of the granules.

$\mathrm{Mg}^{++}$-activated ATPase activity was estimated in hypotonic $(25 \mathrm{~mm}) \mathrm{KCl}$ solution, other conditions being as in the experiment in isotonic $\mathrm{KCl}$ solution. In hypotonic $\mathrm{KCl}$ solution $\mathrm{Mg}^{++}$-activated ATPase was again inhibited about $50 \%$ by $2.5 \mathrm{~mm}$ EGTA. As shown in Fig. 4, maximum inhibition was observed with $1.0 \mathrm{~mm}$ EGTA. On raising the $\mathrm{Ca} /$ EGTA ratio, the $\mathrm{Mg}^{++}$-activated ATPase activity was progressively restored and it was completely restored to the control level at a lower $\mathrm{Ca} / \mathrm{EGTA}$ ratio than in isotonic solution. In medium containing equimolar amounts of $\mathrm{Ca}^{++}$and EGTA, the $\mathrm{Mg}^{++}$-activated ATPase activity was above the control value (Fig. 3). Similar results were obtained at a final EGTA concentration of $5 \mathrm{~mm}$. 


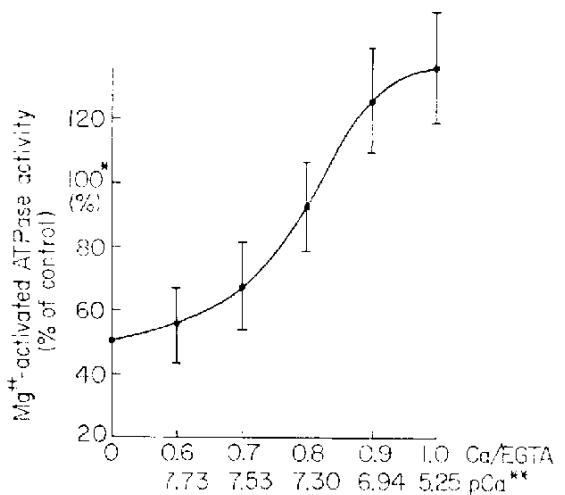

FIG. 3. $\mathrm{Mg}^{++}$-activated ATPase activity of adrenal medullary granules in hypotonic $\mathrm{KCl}$ mediun with various $\mathrm{Ca} / \mathrm{EGTA}$ ratios.

The procedure was as for Fig. 2, except that the final concentration of $\mathbf{K C l}$ was $25 \mathrm{~mm}$. The values represent the means of 4 experiments and the standard deviation are indicated by vertical I-shaped bars.

$* 100 \%$ activity $=0.51 \pm 0.06$ emoles $\mathrm{Pi}$ $\mathrm{mg}$ prot/minutes ( $\mathrm{n}-\mathrm{=}$ )

** pCa : Calculated value of free $\mathrm{Ca}^{++}$

4) Effect of ionic strength on $\mathrm{Mg}^{++}$ activated ATPase

Since the effects of EGTA and CaEGTA on $\mathrm{Mg}^{++}$-activated ATPase activity were grcater in hypotonic $\mathrm{KCl}$ solution than in isotonic $\mathrm{KCl}$ solution, we cxamined the effect of the ionic strength of $\mathrm{KCl}$ on $\mathrm{Mg}^{++}$-activated ATPase. The $\mathrm{Ca}^{++}$-sensitivity of $\mathrm{Mg}^{++}$ activated ATPase was measured as the difference between the activities in the presence of $2.5 \mathrm{~mm}$ of Ca-EGTA and of EGTA, that is the maximum and minimum activities, respectively. As shown in Fig. 5 the $\mathrm{Ca}^{++}$-sensitive activity of $\mathrm{Mg}^{++}$-activated ATPase decreased on increasing the $\mathrm{KCl}$ concentration in the incubation medium. Potassium was not specific for this effect of ionic strength on the action of $\mathrm{Ca}^{++}$, for sodium or Tris ion could replace potassium.

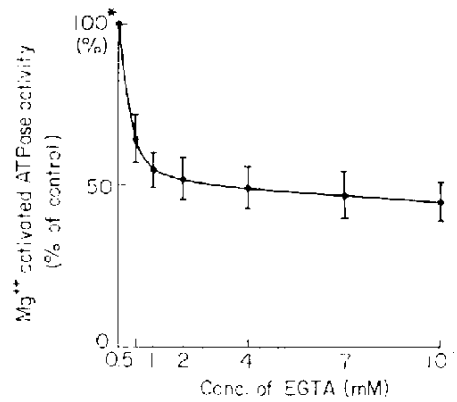

FIG. 4. Effect of EGTA on $\mathrm{Mg}^{++}$-activated ATPase in hypotonic $\mathrm{KCl}$ solution.

The incubation medium contained 4 mм АTP, 2 mм $\mathrm{MgSO}_{*}, 40 \mathrm{~mm}$ Tris $(\mathrm{pH}$ $7.3), 25 \mathrm{~mm} \mathrm{KCl}$, about $2 \mathrm{mg}$ protein of granules and various concentrations of EGTA. The reaction was carried out for 5 minutes at $37^{\circ} \mathrm{C}$. The values represent the means of 3 experiment and standard deviation are indicated by vertical Ishaped bars.

* $100 \%$ activity $=0.51 \pm 0.06 \mu$ moles $\mathbf{P i} /$ mg protiminutes $(n-7)$

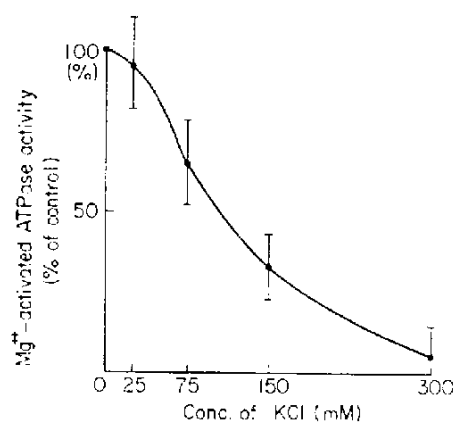

FiG. 5. Effect of ionic strength on $\mathrm{Ca}^{++}$-sensitive activity of $\mathrm{Mg}^{++}$-activated ATPase of adrenal medullary granules.

The incubation medium contained 40 mм Tris ( $\mathrm{pH}$ 7.3), $4 \mathrm{~mm}$ ATP, $2 \mathrm{~mm}$ $\mathrm{MgSO}_{4}$, about $2 \mathrm{mg}$ protein of granules and the various concentrations of $\mathrm{KCl}$ shown, with $2.5 \mathrm{~mm}$ EGTA or Ca-EGTA. The reaction was carricd out for 5 minutes at $37 \mathrm{C}$. The values represent the means of 3 cxperiments and the standard deviation are indicated by vertical Ishaped bars.

* $100 \%$ activity $=0.41 \pm 0.05 \mu$ moles $\mathrm{Pi} /$ mg prot/minutes $(n=6)$ 
5) Time course of the $\mathrm{Mg}^{++}$-activated ATPase reaction in the presence of EGTA or Ca-EGTA

The time course of the $\mathrm{Mg}^{++}$-activated ATPase reaction was examined in hypotonic $\mathrm{KCl}$ medium. In the presence of $2.5 \mathrm{~mm}$ EGTA, the reaction was linear during the first $20 \mathrm{~min}$ of incubation. With $\mathrm{Ca}$-EGTA, $\mathrm{Mg}^{++}$-activated hydrolysis of ATP was linear during the first 5 minutes and then gradually decreased (Fig. 6).

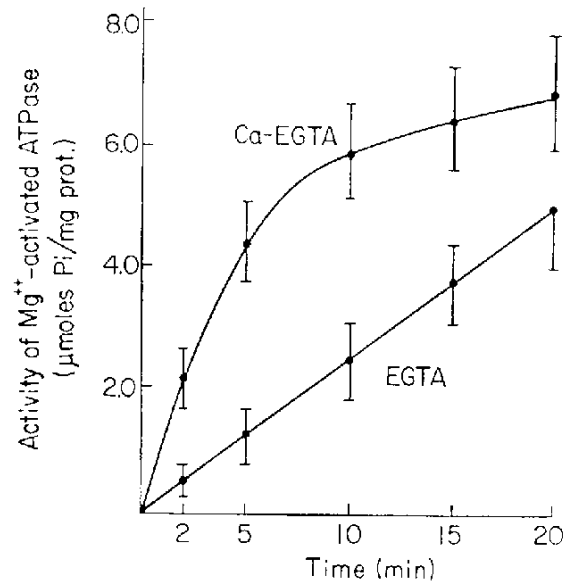

FiG. 6. Time course of $\mathrm{Mg}^{++}$-activated ATPase reaction in the presence of Ca-EGTA or EGTA.

The incubation medium contained 25 $\mathrm{mm} \mathrm{KCl}, 40 \mathrm{~mm}$ Tris ( $\mathrm{pH} \mathrm{7.3),} 4 \mathrm{~mm}$ ATP, $2 \mathrm{mM} \mathrm{MgSO}_{4}$ and about $2 \mathrm{mg}$ protein of granules. Either Ca-EGTA or EGTA was added at the concentration of $2.5 \mathrm{~mm}$. The final volume of the incubation medium was $4 \mathrm{ml}$. The reactions was carried out at $37 \mathrm{C}$. The values represent the means of 4 experiments and the standard deviation are indicated by vertical I-shaped bars.

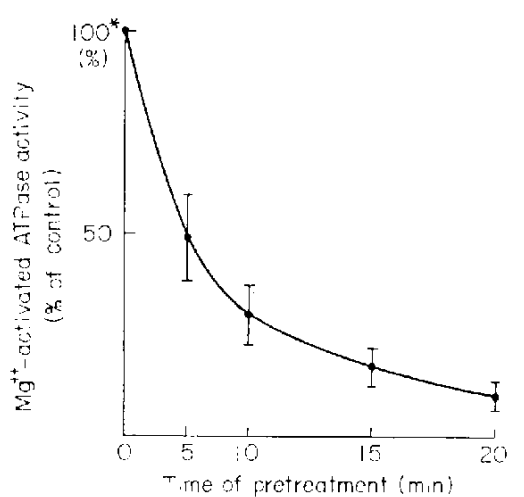

FIC. 7. Heat denaturation of the $\mathrm{Ca}^{++}$-sensitive activity of $\mathrm{Mg}^{++}$-activated ATPase in adrenal medullary granules.

The incubation medium contained 4 mu ATP, 2 mm MgSO 4 , 40 mm Tris $(\mathrm{pH}$ 7.3), $25 \mathrm{~mm} \mathrm{KCl}$ and about $2 \mathrm{mg}$ protein of granules. EGTA or Ca-EGTA was presented. The reaction was carried out for 5 minutes at $37 \mathrm{C}$. The values represent the means of 3 experiments and the standard deviation are indicated by vertical I-shaped bars.

* $100 \%$ activity $=0.41 \pm 0.05$ /moles $\mathrm{Pi}$; mg prot/minutes $(n-6)$.

\section{6) Stability of $\mathrm{Mg}^{++}$-activated ATPase}

The granules were lysed with $25 \mathrm{~mm} \mathrm{KCl}$ in $40 \mathrm{~mm}$ Tris-HCl buffer $(\mathrm{pH} 7.3)$ and then preincubated at $37 \mathrm{C}$ for the various periods shown in Fig. $7 . \mathrm{Mg}^{++}$-activated ATPase activity was estimated under standard conditions except that the final concentration of $\mathrm{KCl}$ was $25 \mathrm{~mm}$. The reaction was carricd out at $37 \mathrm{C}$ for 5 minutes. The effect of $\mathrm{Ca}^{++}$on $\mathrm{Mg}^{++}$-activated ATPase activity was expressed as described above. As shown in Fig. 7 , the effect of $\mathrm{Ca}^{++}$on $\mathrm{Mg}^{++}$-activated ATPase decreased gradually on preincubation without ATP, and after preincubation for 5 minutes at $37 \mathrm{C}$ the effect of $\mathrm{Ca}^{++}$was about half the control level.

\section{DISCUSSION}

The existence of $\mathrm{Mg}^{++}$-activated ATPase in adrenal medullary storage granules and its possible role in the uptake and release of catecholamine by the granules have been re- 
ported by several workers (4-9). Calcium ions are essential for the release of catecholamine from perfused adrenal $(11,12)$ or adrenal slices (19) by acetylcholine or a high potassium concentration. It is generally thought that free $\mathrm{Ca}^{++}$penetrating into the chromaffine cells due to the addition of acetylcholine or a high potassium concentration may initiate the release of catecholamines from the granules in some way (13). But the intracellular mechanism of the action of $\mathrm{Ca}^{++}$is unknown.

Accordingly, we examined the effect of a low concentration of $\mathrm{Ca}^{++}$on the $\mathrm{Mg}^{++}$ activated ATPase aclivity of the granules and on ATP- $\mathrm{Mg}^{++}$stimulated catecholamine release from the granules.

As shown in Fig. 1, EGTA, which chelates with calcium was found to inhibit the $\mathrm{Mg}^{++}$activated ATPase activity of the granules. This inhibitory effect of EGTA on $\mathrm{Mg}^{++}$-activated ATPase activity was not influenced by various concentrations of $\mathrm{Mg}^{++}$, suggesting that the effect of EGTA was due to its removal of contaminating $\mathrm{Ca}^{++}$from the incubation medium. EGTA also strongly inhibited the ATP- $\mathrm{Mg}^{++}$stimulated release of catecholamine.

Next we used Ca-EGTA buffer to oblain a low concentration of calcium ions into the incubation medium. The ratio of $\mathrm{Ca}^{+++}$to EGTA was varied from zero to 1.0 keeping the total amounts of EGTA at $2.5 \mathrm{~mm}$. On raising the $\mathrm{Ca} / \mathrm{EGTA}$ ratio, the $\mathrm{Mg}^{++}$-activated ATPase activity was progressively restored and with equimolar amounts of $\mathrm{Ca}^{++}$and EGTA, the $\mathrm{Mg}^{++}$-activated ATPase activity was restored to $96 \%$ of the control level. Inhibition of catecholamine release by EGTA was also reversed by Ca-EGTA, though to a lesser extent. The fact that the reversal of inhibition of catecholamine release was less than that of $\mathrm{Mg}^{++}$activated ATPase activity might be due to increase in the ionic strength of the medium, in the former case, an inevitable results of adjusting the $\mathrm{pH}$ of the preparation of Ca-EGTA buffer, since ATP- $\mathrm{Mg}^{++}$stimulated release of catecholamine is known to be very sensitive to increase in ionic strength.

Therefore, the results suggest that a low concentration of calcium may be important for the activity of $\mathrm{Mg}^{++}$-activated ATPase of catecholamine containing granules and for the release of catecholamine stimulated by ATP and $\mathrm{Mg}^{++}$.

Wc also examined the effects of EGTA or Ca-EGTA on the $\mathrm{Mg}^{++}$-activated ATPase in hypotonic $\mathrm{KCl}$ medium to see whether the intact structure of the granules was necessary for the effects of these agents on $\mathrm{Mg}^{++}$-activated ATPase. The inhibitory effect of EGTA on $\mathrm{Mg}^{++}$-activated ATPase and its reversal by Ca-EGTA were also observed in hypotonic $\mathrm{KCl}$ medium, suggesting that the intact structure of catecholamine storage granules is not necessary for the effects of these agents. In hypotonic solution the inhibitory effect of EGTA was restored to the control lovel at a lower ratio of $\mathrm{Ca} / \mathrm{EGTA}$ and with equimolar amounts of $\mathrm{Ca}^{++}$and EGTA, $\mathrm{Mg}^{++}$-activated ATPase activity was above the control level. These findings suggest that $\mathrm{Mg}^{++}$-activated ATPase in the granules may be more sensitive to $\mathrm{Ca}^{++}$in hypotonic $\mathrm{KCl}$ solution or that the effect of a low concentration of $\mathrm{Ca}^{++}$may be antagonized by potassium ion. To study these possibilities we examined the effect of ionic strength on the action of $\mathrm{Ca}^{++}$on $\mathrm{Mg}^{++}$-activated ATPasc. The stimulatory effect of $\mathrm{Ca}^{++}$on $\mathrm{Mg}^{++}$-activated ATPase decreased on increasing the potassium concentration. 
Sodium or Tris ion could replace potassium ion. Therefore, the fact that the effects of EGTA and Ca-EGTA are less in isotonic $\mathrm{KCl}$ solution than in hypotonic solution could be explained by the higher ionic strength of the forner medium. Under isotonic conditions the effect of $\mathrm{Ca}^{++}$on the $\mathrm{Mg}^{++}$-activated ATPase seems to be small. The actual concenttration of free calcium in the medium at various Ca/EGTA ratios was not measured but calculated according to Schwarzenbach (20). The concentration of free calcium which is associated with the $\mathrm{Mg}^{++}$-activated ATPase and ATP- $\mathrm{Mg}^{++}$stimulated catecholamine release seems to be about $10^{-7}$ to $10^{-5} \mathrm{M}$.

When the total EGTA concentration was $5 \mathrm{~mm}$ and the Ca/EGTA ratio was 0.8 , the free concentration of EGTA seems to be $1 \mathrm{~mm}$. As shown in Fig. 4, at this concentration EGTA exhibited maximum inhibition of $\mathrm{Mg}^{++}$-activated ATPase. Therefore, the possibility that EGTA acts directly on the granules and that the reversal of inhibition by Ca-EGTA is due to decrease in the free EGTA concentration is excluded.

The effect of $\mathrm{Ca}^{++}$on the $\mathrm{Mg}^{++}$-activated ATPase was greater during a short incubation period (Fig. 6) and was not observed after heat denaturation, so that the sensitivity of $\mathrm{Mg}^{++}$ activated ATPase to $\mathrm{Ca}^{++}$is very unstable to heat.

The fact that the maximum inhibitory effect of EGTA on $\mathrm{Mg}^{++}$-activated ATPase in intact granules was $40 \%$ of the tolal activity raises the question of the physiological role of FGTA resistant $\mathrm{Mg}^{++}$-activated ATPase. Addition of EGTA to the incubation medium significantly increased the uptake of ${ }^{14} \mathrm{C}$-adrenaline into the granules unpublished. Thus EGTA resistant $\mathrm{Mg}^{++}$-activated ATPase may be related to the uptake of catecholamine.

From these data, it seems that a low concentration of calcium penetrating the chromaffine cells, due to the presence of acetylcholine or a high potassium concentration, may activate the $\mathrm{Mg}^{++}$-activated ATPase of these granules and this activation, in turn, may cause catecholamine release from the granules.

\section{SUMMARY}

The effect of $\mathrm{Ca}^{++}$on the $\mathrm{Mg}^{++}$-activated ATPase (ATP Phosphohydrolase, EC, 3, $6,1,4)$ activity and on ATP- $\mathrm{Mg}^{++}$stimulated catcholamine release from bovine adrenal medullary granules was studied.

1. The chelating agent, EGTA inhibited the $\mathrm{Mg}^{++}$-activated ATPase activity of the granules. EGTA also strongly inhibited the ATP- $\mathrm{Mg}^{++}$stimulated release of catecholamine from the granules.

2. Addition of $\mathrm{Ca}^{++}$at a concentration equimolar to that of EGTA prevented the inhibition of $\mathrm{Mg}^{++}$-activated ATPase by EGTA. Inhibition of catecholamine release by EGTA was also reversed by addition of $\mathrm{Ca}^{++}$.

3. The inhibitory effect of EGTA on $\mathrm{Mg}^{++}$-activated ATPase and its reversal by $\mathrm{Ca}-$ EGTA were also observed in the disrupted granules.

4. These results suggest that a low concentration of $\mathrm{Ca}^{++}$may be important for the activity of $\mathrm{Mg}^{++}$-activated $\mathrm{ATPase}$ of the granules and for the release of catecholamine stimulated by ATP and $\mathrm{Mg}^{++}$. 
Acknowledgement: We wish to thank Prof. R. Imaizumi and H. Yoshida for their advice and encouragement. We also thank Mrs. K. Tsuji for her technical assistance.

\section{REFERENCES}

1) Hillakp, N.Å.: Acta physiol. scand. 42, 144 (1958)

2) Banks, P.: Biochem. J. 95, 490 (1965)

3) Kirshiner, N., Kirshner, A.G. and Kamin, D.L.: Biochim. biophys. Acta 113, 332 (1966)

4) Kirshner, N.: J, Biol. Chem. 237, 2311 (1962)

5) Carlsson, A., Hillarp, N.A. And Waldeck, B.: Acta physiol. scand. 59, (suppl. 251) l (1963)

6) Taugner, G. and Hasselbach, W.: Arch. Pharmak. exp. Path. 260, 58 (1968)

7) OKa, M., Ohuch, T., Yoshida, H. and Imaizumi, R.: Biochim. biophys. Acta 97, 170 (1965)

8) OKa, M., Ohuchi, T., Yoshida, H. and Imatzumi, R.: Jap. J. Pharmac. 17, 199 (1967)

9) Poisner, A.M. and Trifarö, J.M.: Mol. Pharmac. 3, 561 (1967)

10) ОкА, M. and Izumi, F.: Jap. J. Pharmac. 21, 680 (1971)

11) Douglas, W.W. and Rubin, R.P.: J. Physiol. 159, 40 (1961)

12) Douglas, W.W. and Rubin, R.P.: J. Physiol. 167, 288 (1963)

13) Douglas, W.W. and Poisner, A.M.: J. Physiol. 162, 385 (1962)

14) Oka, М., Ohuchi, T., Yoshida, H. and Imaizumi, R.: Life Sciences 5, 427 (1966)

15) Takahashi, Y.: J. Japan. Biochom. Soc. 26, 690 (1955) (in Japanese)

16) Lowry, O.H., Rosfrrough, N.J., Farr, A.L. and Randall, R.J.: J. biol. Chem. 193, 265 (1951)

17) Well-Malherbe, H.: Biochem. J. 51, 311 (1952)

18) Portzehll, H., Caldwell, P.C. and Ruegg, J.C.: Biochim. biophys. Acia 79, 581 (1964)

19) OKa, M., Ohuchi, T., Yoshida, H. and Imaizumi, R.: Jap. J. Pharmac. 15, 348 (1965)

20) Schwarzenbach, G. avd Willi, A.: Helv. chim. Acta 34, 528 (1951) 